\section{Corrupted science?}

Wilfred Beckerman

The Death of Economics. By Paul Ormerod. Faber: 1994. Pp. 230. £14.99.

THE worst thing about this book is its title. It ought to have been called "The Birth of Economics". The author asserts that the state of economics today is very much as it was in the Middle Ages, which may be true. In 1956, I published an article in The Economic Journal saying more or less the same thing, so I was naturally receptive to this part of Ormerod's message. But modern science was not in its death-throes in the Middle Ages; it was just getting going. The same applies to economics today. Many of Ormerod's very valid criticisms of most orthodox macro-economic theory originate, as he concedes, from within the economic profession itself. So economics is quite an active infant. Whether it will grow up properly, however, is another matter.

As Ormerod points out, economics was hijacked in the nineteenth century by a desire to emulate the mathematical approach that seemed to be so successful in the natural sciences. Consequently, promotion and prestige in the subject depend as much, if not more, on demonstrating technical mathematical ability rather than on genuine insight and imagination, let alone the familiarity with institutional constraints that characterized the work of the great earlier economists, such as Adam Smith, Ricardo and Malthus. Ormerod asserts, probably correctly, that there is an "internal culture in economics extolling esoteric irrelevance".

But Ormerod's evidence for his view is seriously flawed. For example, among the criticisms he makes of orthodox economics are: inadequate attention to the role of the share of profits in national income in explaining fluctuations in output and long-term growth; excessive reliance on bad simplifying assumptions; lack of appreciation of what goes on in the real world; excessive resort to mathematical hocus-pocus; and inadequate linkage of models of fluctuations with longer-run growth.

Yet, strangely enough, he completely overlooks the work of great economists such as Sir Roy Harrod or the Polish economist Michal Kalecki, who were certainly not guilty of any of these failings. $\mathrm{He}$ does refer, disparagingly, to one of Keynes's closest disciples, Richard Kahn, but persists in spelling his name as "Khan", which can be very misleading: readers may get him mixed up with many other Khans, such as Genghis Khan, the Aga Khan or Imran Khan.

Unlike Ormerod, Kalecki did not be- lieve that economists really had much influence. Policy is determined by what the politicians want. Whatever policy they want to adopt - such as a deflationary policy in order to redress the balance of power in society and wrest it back from the trade unions - they will, as Kalecki warned back in 1960, find economists to provide theoretical justifications for their practical policies.

It is not the excessive mathematics and the adoption of absurd assumptions in order to make trivial problems mathematically soluble that will prevent the healthy development of economics. For it might be hoped that, as time goes by and economics grows up, every professional economist will have a good grasp of mathematics, so that kudos would go only - as in the natural sciences - to those with creative ideas. The wicked fairy's curse on economics at its birth was that economists would suffer the corrupting influence of trying to serve some political group or other, or their own ideological preferences. Natural scientists are less subject to this temptation, which is why the outlook for economics is not so bright.

When Ormerod discusses the weaknesses of micro-economics, he is again on rather weak ground. One of the main specific instances he provides of the weakness of orthodox economics is the issue raised by environmentalists, namely the problem of the exhaustion of finite resources. In orthodox economics, as he explains, a shortage of any material would lead to a rise in its price, with all sorts of feedbacks that would tend to increase supply and reduce demand. And this is what has actually happened. The contrary predictions made in 1972 in The Limits to Growth, a ludicrous study which Ormerod generously praises, have been totally falsified by events.

The crowning inconsistency between Ormerod's general criticisms and his specific examples lies in his own attempt to escape from the constraints of what he calls orthodox economics. For, after spending five chapters criticizing modern macro-economic theory's excessive respect for mathematical modelling, our hero then makes a great bound and escapes by means of his own model, which miraculously works thanks to the special gadgets he has installed, including nonlinearity in the equations, chaos theory, "attractor points" and so on.

However, despite the many defects in the details of the book, it is still an admirably lucid, well-written and informative read for the layman and even for those professional economists who ought to be more humble than they are. But the author displays a patchy knowledge of the literature and an inconsistency between his diagnosis and his own solution; and, by failing to spot the political element, the diagnosis is probably false to begin with anyway.

Wilfred Beckerman is at $1 \mathrm{c}$ Norham Gardens, Oxford OX2 6PS, UK.

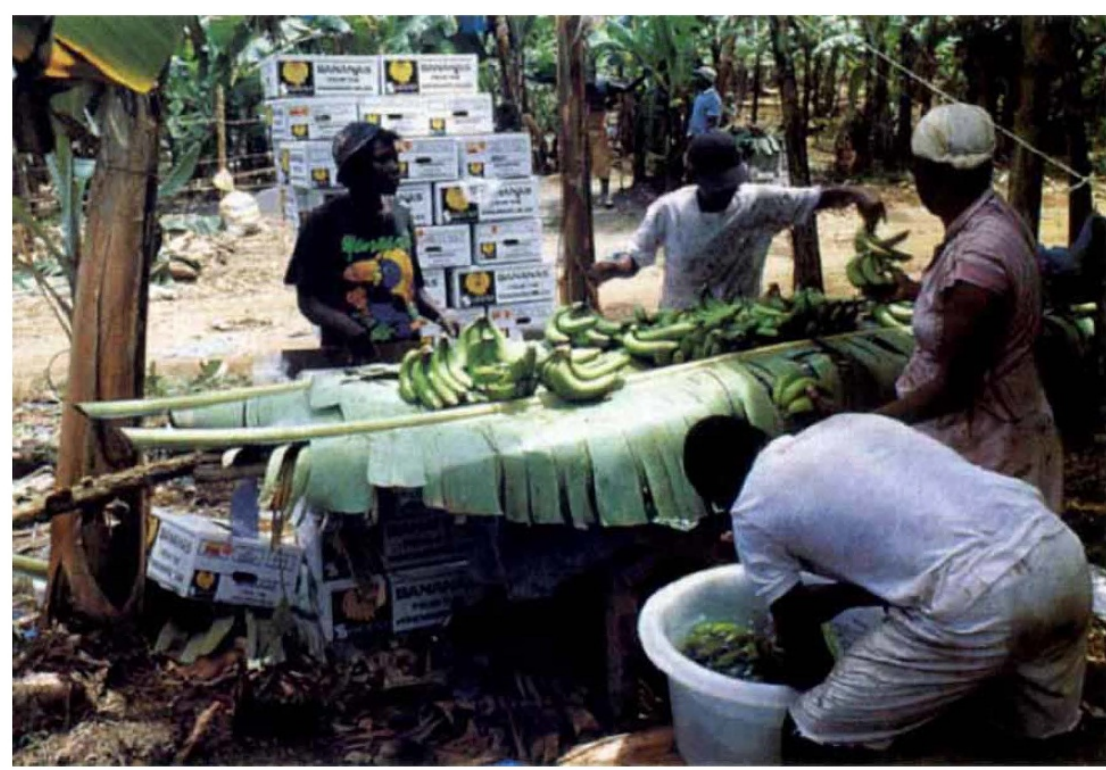

TAX.FREE bananas - eastern Caribbean islanders depend on bananas for half their income. Taken from The Gaia Atlas of Planet Management edited by Norman Myers. Now revised and extended, the atlas provides a wealth of information on environmental and political changes that affect our planet (Gaia Books, £16.99 (pbk)). 